- Notes -

\title{
Cascade Extraction and Separation of the Active Constituents from Jatropha Curcas L. Seeds
}

\author{
Jing LIU, ${ }^{1}$ * Pan CHEN, ${ }^{1}$ Long RONG, ${ }^{2}$ Jiandu LEI, ${ }^{1}$ Jing HE, ${ }^{1}$ Lihong DENG ${ }^{1}$ and Luying WANG ${ }^{1}$ \\ ${ }^{1}$ MOE Key Laboratory of Wooden Material Science and Application, Beijing Forestry University, Beijing \\ 100083, P. R. China \\ ${ }^{2}$ Key Laboratory for Biomechanics and Mechanobiology of Ministry of Education, Beihang University, \\ Beijing 100191, P. R. China
}

(Received August 4, 2014; Accepted September 26, 2014)

A new method of cascade extraction and separation of active constituents from Jatropha curcas L. seeds was designed to explore the multi-utilization of Jatropha oil cake. Effort has been devoted to convert the Jatropha oil cake into high value-added products. The Jatropha oil was extracted by an ultrasonic method and other active constituents were prepared by means of flash extraction and resin chromatography etc.; the Jatropha oil was analyzed by GC-MS and the contents of the active constituents were determined by UV spectrophotometry. The yields of Jatropha oil and the active constituents were as follows, Jatropha oil $37.42 \mathrm{~g} / 100 \mathrm{~g}$ dry seeds, polysaccharide $0.46 \mathrm{~g} / 100 \mathrm{~g}$ dry seeds (purity $75.72 \%$ ), protein $2.06 \mathrm{~g} / 100 \mathrm{~g}$ dry seeds (purity $72.61 \%$ ), respectively. Furthermore, the contents of flavone was $0.90 \mathrm{~g} / 100 \mathrm{~g}$ dry seeds, phytosterol was $0.50 \mathrm{~g} / 100 \mathrm{~g}$ dry seeds, anthocyanin was $0.12 \mathrm{~g} / 100 \mathrm{~g}$ dry seeds and alkaloids was 1.90 $\mathrm{g} / 100 \mathrm{~g}$ dry seeds. Additionally, the molecular weight and antioxidant activity of polysaccharides from Jatropha curcas L. seeds were also evaluated.

\section{Introduction}

Jatropha curcas Linnaeus is a multipurpose plant belonging to the Euphorbiaceae family, it has a wide range of uses and promises various significant benefits to humans and industry [1]. The plant produces many useful products. For example, the leaves are used in traditional medicine as an antiseptic and the latex produced from the branches can be used as a haemostatic agent [2]. Particularly, the seeds are a good source of oil, which can be used as a diesel substitute after some treatment, such as transesterification and hydrotreatment [3]. The oil from the seeds has also been found useful for medicinal and veterinary purposes, such as an insecticide [4]. After extraction of the oil, the oil cake is rich in protein, but it is toxic to rats, mice and ruminants and therefore cannot be used as an animal feed [5]. This by-product has not been comprehensively studied, therefore limited information is available on the feasible applications of the oil cake as a potential source of bioactive compounds [6]. The high cost of petroleum oil and recent reports on an increase in the amount of oil cake produced during the Jatropha oil production has created a need to convert large quantities of Jatropha oil cake into value-added products.

Recently, some studies of Jatropha oil cake have been devoted to proteins and phorbol esters including nutritional value, chemical composition, biological activities, and biodegradation [7-10]. Less attention has been paid to the other active constituents of Jatropha curcas L. seeds, such as polysaccharides 
[11], flavones [12], phytosterol [13], anthocyanin [14], and alkaloids [15]. Additionally, while Jatropha oil is the main product, the process of extracting and isolating the other active constituents from Jatropha curcas L. seeds has not been completely explored. This would be a shocking waste of the natural resources. The aim of the present paper was therefore to provide a solid base for the multi-utilization of Jatropha oil cake. In this work, flash extraction and isolation of several active constituents from Jatropha curcas L. seeds were investigated. All the active constituents could represent economic value-added products in the development and utilization of Jatropha oil cake. Moreover, many studies have demonstrated that the molecular weight distributions of polysaccharides had a great influence on their biological activities [16]. Thus, a polysaccharide sample was prepared and its in vitro antioxidant activities were evaluated using its hydroxyl radical scavenging ability.

\section{Experimental}

\subsection{Materials and chemicals}

Jatropha curcas L. seeds were purchased from Jiangsu Donghu Bioenergy Co., Ltd. The D213 resin was obtained from the 3rd Chemical Factory of Dandong. Ethanol, $n$-hexane and all other chemicals were of analytical reagent grade.

\subsection{Ultrasonic extraction of Jatropha oil}

A Ultrasonic Extractor (SY-1000E, Beijing Hongxianglong Biotechnology Developing Co. Ltd., China) was used for ultrasonic extraction. The Jatropha curcas L. seeds were ground into a powder (20 mesh). Then the seed powder $(24 \mathrm{~g})$ and $480 \mathrm{~mL}$ of a mixed solvent $(384 \mathrm{~mL}$ ethanol and $96 \mathrm{~mL}$ hexane) were placed in the container and thoroughly macerated for $15 \mathrm{~min}$. The ultrasonic probe was fixed at a defined position. Then the mixture was extracted under $20 \mathrm{KHz}$ for $30 \mathrm{~min}$ at room temperature. The mixture was then centrifuged at $5000 \mathrm{rpm}$ for $10 \mathrm{~min}$. The supernatant liquid was evaporated under reduced pressure (rotary evaporation) at $55^{\circ} \mathrm{C}$, and

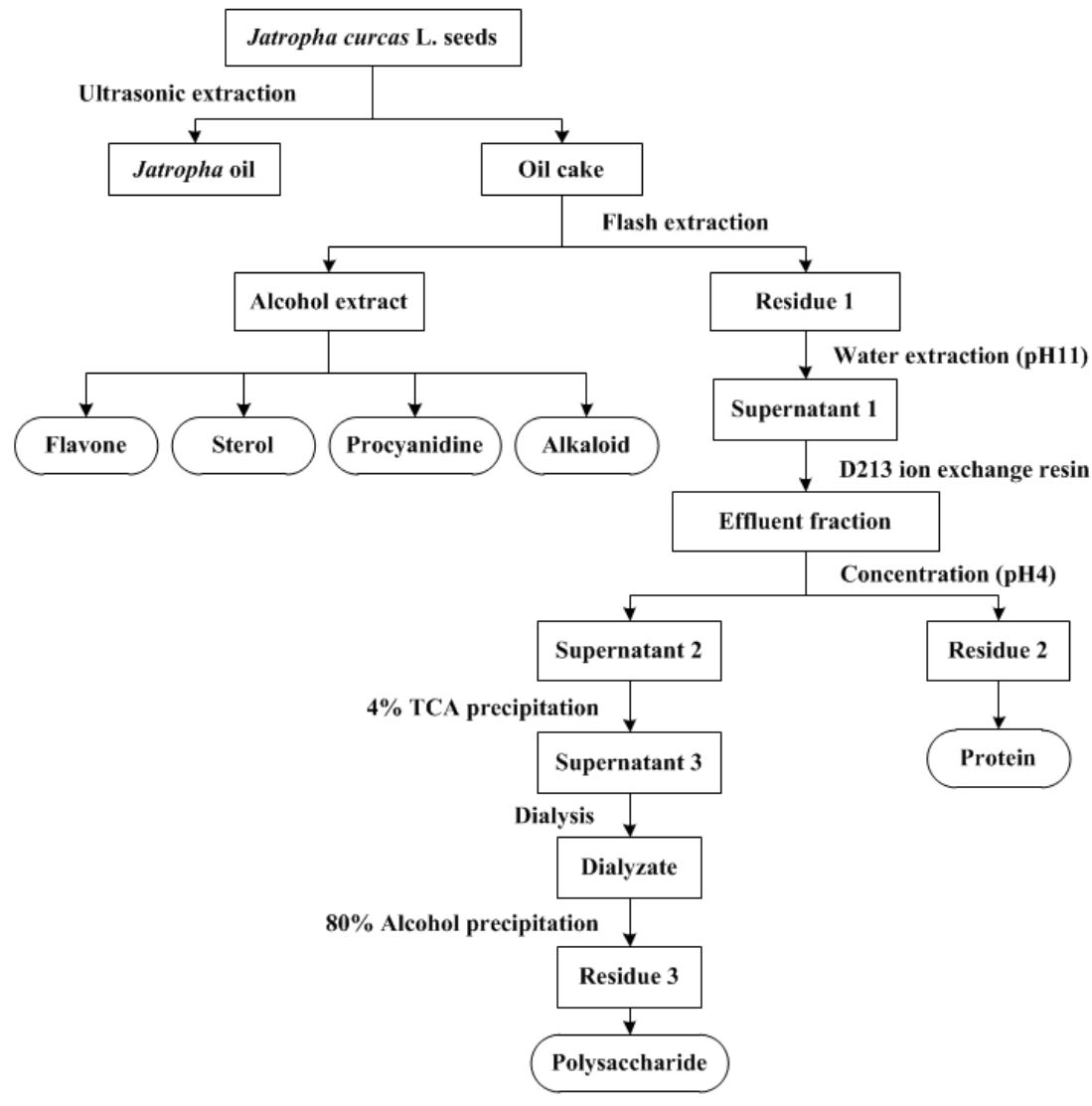

Figure 1. Process flow diagram of the cascade extraction and separation of Jatropha curcas L. seeds. 
the extracted oil was collected. The process flow of the cascade extraction and product recovery is showed in Figure 1.

\subsection{Cascade description}

The precipitate was processed as follows. (1) Flash extraction: The alcohol extracts were obtained firstly. The oil cake and 95\% ethanol were put in a Herbal Blitzkrieg Extractor [17], and extracted twice. Then the alcohol extract was determined according to section 2.4; (2) Alkaline water extraction: Mainly protein will be obtained by the method of alkali extraction and acid precipitation. Thus, to residue 1 was added distilled water at $\mathrm{pH} 11$ and the mixture stirred for $2 \mathrm{~h}$ at $45^{\circ} \mathrm{C}$, and centrifuged at $5000 \mathrm{rpm}$ for 15 min; (3) Depigmentation: In order to improve the purity of the protein, the water extract solution needs to have the pigment removed. So supernatant 1 was treated with D213 base ion exchange resin, then the column effluent fraction was recovered and evaporated under reduced pressure at $80^{\circ} \mathrm{C}$; (4) Acid precipitation: The acid protein will be precipitated under acidic conditions. The concentrated solution was adjusted to $\mathrm{pH} 4$, then residue 2 was dried and protein was obtained; (5) Deproteinization: Supernatant 2 may contain a very small amount of protein. This will be precipitated together with polysaccharide by $80 \%$ ethanol in the next procedure. Thus, the residual protein should be removed from supernatant 2 to improve the purity of the polysaccharide. Therefore, supernatant 2 was treated with $4 \%$ trichloroacetic acid (TCA) and put in a freezer at $4^{\circ} \mathrm{C}$ for $2 \mathrm{~h}$, then centrifuged at $5000 \mathrm{rpm}$ for $15 \mathrm{~min}$; (6) Dialysis: In order to remove small molecule impurities, supernatant 3 was concentrated and enclosed within a dialysis bag (molecular weight cut off 10000-14000), then water was added and dialyzed overnight; (7) Alcohol precipitation: The polysaccharide will be precipitated by $80 \%$ ethanol. Thus, $80 \%$ ethanol was added to the dialyzate and centrifuged at $5000 \mathrm{rpm}$ for $15 \mathrm{~min}$, then residue 3 was dried and polysaccharide was obtained.

\subsection{Quantitative analysis}

\subsubsection{Jatropha curcas $\mathrm{L}$. seeds oil}

Gas chromatography-mass spectrometry (GC-MS) was used for analyzing the composition of Jatropha seed oil. An Agilent 7890A/5975C GC-MS system was employed using a HP-5MS column (30 m $\times 0.25 \mathrm{~mm}$ i.d. $\times 0.25 \mu \mathrm{m}$ film thickness) with $\mathrm{He}$ as the carrier gas. The column temperature of the GC was programmed to hold from the initial temperature of $100^{\circ} \mathrm{C}$ at $3^{\circ} \mathrm{C} / \mathrm{min}$ to $240^{\circ} \mathrm{C}$, where it was held for $3 \mathrm{~min}$, with a total run time of $49.66 \mathrm{~min}$. The inlet temperature was maintained at $250^{\circ} \mathrm{C}$, and the split ratio was 20:1. Analysis with a mass detector was carried out under the following conditions: helium as the carrier gas, an electron energy of $70 \mathrm{eV}$, and a mass range from 35 to 450 .

Before GC-MS analysis, the fatty acids of the extracted Jatropha curcas seed oil were derivatized into their methyl esters $[18,19]$. The Jatropha curcas seed oil was weighed $(100 \mu \mathrm{L})$ and dissolved in $4 \mathrm{~mL}$ isooctane. $200 \mu \mathrm{L}$ of a $2 \mathrm{~mol} / \mathrm{L}$ potassium hydroxide methanol solution was then added to the test tube, stirred, and held at room temperature for $30 \mathrm{~min}$. Finally, $1 \mathrm{~g}$ of sodium bisulfate was added and stirred, then the filtrate was injected into a GC-MS system for analysis. Quantitative analysis of the fatty acids was determined by measuring peak areas.

\subsubsection{Polysaccharide}

The polysaccharide sample was determined by the Phenol-Sulfuric acid method [20,21] with minor modification. The calibration curve for glucose $(2.90-17.10 \mu \mathrm{g} / \mathrm{mL})$ was prepared by plotting concentration of glucose versus absorbance. The linear regression equation was: $A_{488}=0.0568 C-0.0046(r=0.9996)$, 
where $\mathrm{A}_{488}$ is the absorbance at $488 \mathrm{~nm}$ and $\mathrm{C}$ is the concentration of the glucose sample $(\mu \mathrm{g} / \mathrm{mL})$. In this method, $1 \mathrm{~mL}$ of the polysaccharide sample solution $(0.30 \mathrm{mg} / \mathrm{mL})$ was mixed with $1 \mathrm{~mL}$ of $5 \mathrm{~g} / \mathrm{mL}$ phenol, then $5 \mathrm{~mL}$ of $98 \%$ sulfuric acid was added to the mixture and shaken well. It was then heated for $20 \mathrm{~min}$ in a boiling water bath. After cooling to room temperature for $5 \mathrm{~min}$ in a cold water bath, the mixtures were found to have constant color intensity at room temperature and measured at $488 \mathrm{~nm}$ using a spectrophotometer. Total polysaccharide concentration was calculated using glucose as the standard.

\subsubsection{Protein}

The protein sample was determined by Coomassie brilliant blue methods [22] using bovine serum albumin as the standard. The calibration curve for bovine serum albumin $(4-20 \mu \mathrm{g} / \mathrm{mL})$ was prepared by plotting the concentration of bovine serum albumin versus absorbance. The linear regression equation was: $A_{595}=0.0417 C+0.0313(r=0.9974)$, where $A_{595}$ is the absorbance at $595 \mathrm{~nm}$ and $\mathrm{C}$ is the concentration of bovine serum albumin $(\mu \mathrm{g} / \mathrm{mL})$. In this method, $0.20 \mathrm{~mL}$ of the protein sample solution $(0.50 \mathrm{mg} / \mathrm{mL})$ was diluted to $1 \mathrm{~mL}$ by adding $0.80 \mathrm{~mL}$ of distilled water. Then $4 \mathrm{~mL}$ of $10 \mathrm{mg} / \mathrm{mL}$ Coomassie G250 dye (25 $\mathrm{mL}$ ethanol, $50 \mathrm{~mL} 85 \%$ phosphoric acid and $425 \mathrm{~mL}$ distilled water) was added and the mixture shaken thoroughly. The mixture was allowed to stand for $5 \mathrm{~min}$ and the blue color formed was measured at $595 \mathrm{~nm}$ using a spectrophotometer.

\subsubsection{Flavone}

The aluminum nitrate colorimetric method was modified from the procedure reported by Marı'a I. Nieva Moreno et al. [23]. The calibration curve for rutin $(16-56 \mu \mathrm{g} / \mathrm{mL})$ was prepared by plotting the concentration of rutin versus absorbance. The linear regression equation was: $A_{510}=0.0113 C-0.0026(r=$ $0.9998)$, where $A_{510}$ is the absorbance at $510 \mathrm{~nm}$ and $C$ is the concentration of the rutin sample $(\mu \mathrm{g} / \mathrm{mL})$. In this method, $0.50 \mathrm{~mL}$ of alcohol extract solution (to obtain absorbance in the range of the prepared calibration curve) was mixed with $4.50 \mathrm{~mL}$ of $60 \%$ ethanol. Then $0.50 \mathrm{~mL}$ of $5 \%$ sodium nitrite was added and mixed. After $6 \mathrm{~min}$ at room temperature, $0.50 \mathrm{~mL}$ of a $10 \%$ aluminium nitrate solution was added and mixed. After 6 min at room temperature, $4 \mathrm{~mL}$ of $4 \%$ sodium hydroxide was added and mixed. After 10 $\mathrm{min}$ at room temperature, the absorbance was determined spectrophotometrically at $510 \mathrm{~nm}$. Total flavone concentration was calculated using rutin as the standard.

\subsubsection{Phytosterol}

The phytosterol sample was determined by the phosphorus iron pyrites method [24] using stigmasterol as the standard compound. The calibration curve for stigmasterol $(0.03-0.06 \mathrm{mg} / \mathrm{mL})$ was prepared by plotting the concentration of rutin versus absorbance. The linear regression equation was: $A_{520}$ $=12.408 \mathrm{C}-0.0121(r=0.9983)$, where $\mathrm{A}_{520}$ is the absorbance at $520 \mathrm{~nm}$ and $\mathrm{C}$ is the concentration of the stigmasterol sample $(\mathrm{mg} / \mathrm{mL})$. In this method, $0.50 \mathrm{~mL}$ of alcohol extract solution (to obtain absorbance in the range of the prepared calibration curve) was diluted to $3 \mathrm{~mL}$ by adding $2.50 \mathrm{~mL}$ of ethanol. Then $2 \mathrm{~mL}$ ferric phosphorus iron pyrites reagent $(8 \mathrm{~mL}$ of $25 \mathrm{mg} / \mathrm{mL}$ trichloride-strong phosphoric acid and $92 \mathrm{~mL}$ $98 \%$ sulfuric acid) was added and the mixture shaken thoroughly. The mixed solution was then heated and maintained at $50^{\circ} \mathrm{C}$ for $15 \mathrm{~min}$. After cooling, the mixture was measured at $520 \mathrm{~nm}$ using a spectrophotometer.

\subsubsection{Anthocyanin}

The anthocyanin sample was analysed by the vanillin-sulfuric acid method $[25,26]$ with some 
modification. The calibration curve for procyanidine $(0.01-0.04 \mathrm{mg} / \mathrm{mL})$ was prepared by plotting the concentration of procyanidine versus absorbance. The linear regression equation was: $A_{500}=14.801 \mathrm{C}$ $0.0131(r=0.9978)$, where $\mathrm{A}_{500}$ is the absorbance at $500 \mathrm{~nm}$ and $\mathrm{C}$ is the concentration of the procyanidine sample ( $\mathrm{mg} / \mathrm{mL}$ ). In this method, $1 \mathrm{~mL}$ of the alcohol extract solution (to obtain absorbance in the range of the prepared calibration curve) was mixed with $2.50 \mathrm{~mL}$ of $30 \mathrm{~g} / \mathrm{L}$ vanillin in methanol. Then $2.50 \mathrm{~mL}$ of $30 \%$ sulfuric acid-methanol was added and the mixture shaken thoroughly. It was then maintained at $30^{\circ} \mathrm{C}$ for $20 \mathrm{~min}$ in a dark place. After cooling to room temperature, the mixtures were found to have a constant color intensity and were measured at $500 \mathrm{~nm}$ using a spectrophotometer. Total anthocyanin concentration was calculated using procyanidine as the standard compound.

\subsubsection{Alkaloid}

The alkaloid content was measured by acid dye colorimetry [27,28] using Chuanxiongzine hydrochloride as the standard compound. The calibration curve for Chuanxiongzine hydrochloride (23-122 $\mu \mathrm{g} / \mathrm{mL}$ ) was prepared by plotting the concentration of Chuanxiongzine hydrochloride versus absorbance. The linear regression equation was: $A_{420}=0.0043 C+0.0915(r=0.9911)$, where $A_{420}$ is the absorbance at $420 \mathrm{~nm}$ and $C$ is the concentration of Chuanxiongzine hydrochloride $(\mu \mathrm{g} / \mathrm{mL})$. In this method, $1 \mathrm{~mL}$ of alcohol extract solution (to obtain absorbance in the range of the prepared calibration curve) was transferred to a $50 \mathrm{~mL}$ separator, containing $5 \mathrm{~mL}$ of chloroform and $5 \mathrm{~mL}$ of $2 \mathrm{mg} / \mathrm{mL}$ bromocresol green in a buffer solution $(220.50 \mathrm{~mL}$ of $0.20 \mathrm{M}$ sodium hydrogen phosphate and $279.50 \mathrm{~mL}$ of $0.2 \mathrm{M}$ citric acid at $\mathrm{pH}$ 4.4) After shaking for $3 \mathrm{~min}$, the layers were allowed to separate completely ( $30 \mathrm{~min})$. The chloroform layer was transferred to a second separator, and the aqueous layer was re-extracted with another $10 \mathrm{~mL}$ of chloroform. The combined chloroform extracts were shaken for $15 \mathrm{sec}$ with $10 \mathrm{~mL}$ of $0.10 \mathrm{M}$ $\mathrm{NaOH}$ to liberate the combined dye. After volume adjustment, the intensity of the color of the solution was measured at $420 \mathrm{~nm}$.

\subsection{Molecular weight and antioxidant activity of polysaccharide}

Gel Permeation Chromatography (GPC) is effective in estimating the molecular weight of unknown polymers of similar or identical chemical structures to those used to calibrate columns [29]. In the present study, the molecular weight distribution of polysaccharide was determined using GPC on a PL aquagel-OH 50 column $(300 \times 7.7 \mathrm{~mm}$, Polymer Laboratories Ltd.), calibrated with PL pullulan polysaccharide standards (peak average molecular weights 738, 12200, 100000, 1600000, Polymer Laboratories Ltd.). The column temperature was maintained at $30^{\circ} \mathrm{C}$ and the eluent was $0.02 \mathrm{~N} \mathrm{NaCl}$ in $0.005 \mathrm{M}$ sodium phosphate buffer $(\mathrm{pH} 7.50)$ with a flow rate of $0.50 \mathrm{~mL} / \mathrm{min}$. Detection was achieved with a Knauer differential refractometer. The polysaccharide sample was dissolved with $0.02 \mathrm{~N} \mathrm{NaCl}$ in a $0.005 \mathrm{M}$ sodium phosphate buffer, $\mathrm{pH} 7.50$ at a concentration of $0.10 \%$,and filtered through a $0.45 \mu \mathrm{m}$ filter membrane before analysis.

In this work, the antioxidant activities of the polysaccharide samples were evaluated using their hydroxyl radical $(\cdot \mathrm{OH})$ scavenging ability by a modified method of Dongmei Liu et al [30]. The experimental method was adjusted as following: the reaction mixture contained $1.00 \mathrm{~mL}$ of $2 \mathrm{mmol} / \mathrm{L}$ $\mathrm{FeSO}_{4}, 1 \mathrm{~mL} 6 \mathrm{mmol} / \mathrm{L}$ salicylic acid (dissolved by alcohol), $1 \mathrm{~mL}$ of sample solutions in water at different concentrations $(0-2 \mathrm{mg} / \mathrm{mL})$, and $1.00 \mathrm{~mL}$ of $0.1 \% \mathrm{H}_{2} \mathrm{O}_{2}$. Then the reaction mixture was incubated at $37^{\circ} \mathrm{C}$ for $30 \mathrm{~min}$. In the control, salicylic acid was substituted with distilled water. The absorbance was recorded at $510 \mathrm{~nm}$, and the scavenging activity of the polysaccharide was calculated according to the equation: 
Scavenging effect $(\%)=[1-($ Abs. of sample-Abs. of control $) /$ Abs. of blank $] \times 100 \%$. Ascorbic acid was taken as the positive control.

\section{Results and Discussion}

\subsection{GC-MS analysis of Jatropha curcas L. seeds oil}

The Jatropha seed oil was obtained from ultrasonic extraction and the yield was $37.42 \mathrm{~g} / 100 \mathrm{~g}$ dry seeds. Compared with reflux extraction [31] and microwave extraction [32], ultrasonic extraction showed a high yield. The Jatropha seed oil was analyzed by GC-MS and table 1 shows the content of each fatty acid methyl ester. The GC-MS analysis indicated that the oil contained six fatty acid methyl esters and that they were mainly unsaturated fatty acids. Furthermore, Jatropha seed oil contained large amounts of oleic acid (C18:1) and linoleic acid (C18:2). Compared with the previous papers [31,32], the compositions of Jatropha seed oil were similar, and all Jatropha seed oil contained large amounts of unsaturated fatty acids, which are mainly oleic acid (C18:1) and linoleic acid (C18:2), as shown Table 1.

Table 1. Identification of the compositions of Jatropha seed oil (after methyl esterifying) by GC-MS analysis.

\begin{tabular}{|c|c|c|}
\hline Detected compound & Structure ${ }^{\text {a }}$ & Content (\%) \\
\hline \hline 9-Hexadecenoic acid methyl ester & $\mathrm{C} 16: 1$ & $0.57 \pm 0.01$ \\
\hline Hexadecanoic acid methyl ester & $\mathrm{C} 16: 0$ & $12.01 \pm 0.03$ \\
\hline 9,12-Octadecadienoic acid methyl ester & $\mathrm{C} 18: 2$ & $33.61 \pm 0.07$ \\
\hline 9-Octadecenoic acid methyl ester & $\mathrm{C} 18: 1$ & $45.08 \pm 0.2$ \\
\hline Octadecanoic acid methyl ester & $\mathrm{C} 18: 0$ & $8.12 \pm 0.02$ \\
\hline 3-Eicosenoic acid methyl ester & $\mathrm{C} 20: 1$ & $0.61 \pm 0.01$ \\
\hline
\end{tabular}

${ }^{\mathrm{a}} \mathrm{Cx}$ :y indicates $\mathrm{x}$ carbons in the fatty acid chain with $\mathrm{y}$ double bonds.

\subsection{Analysis of other active constituents}

To the best of our knowledge, this is the first time to report the method of cascade extraction and separation of active constituents to explore the multi-utilization of Jatropha oil cake. The content, yields and purity of the other active constituents obtained from Jatropha curcas L. seeds are summarized in Table 2. In the present study, polysaccharide and protein were obtained with high yield and high purity. Meanwhile, flavone, phytosterol, anthocyanin and alkaloid were qualitatively determined. Taking into account that all constituents were collected from Jatropha oil cake, an industrial waste product from Jatropha seed oil processing, our results strongly emphasise the potential applications of these constituents as economic value-added ingredients in nutraceutical and functional products. 
Table 2. Content, yield and purity of other active constituents in Jatropha curcas L. seeds.

\begin{tabular}{|c|c|c|c|}
\hline Constituents & Content (g/100 g dry seeds) & Yield (g/100 g dry seeds) & Purity (\%) \\
\hline \hline Polysaccharide & 0.35 & 0.46 & 75.72 \\
\hline Protein & 1.50 & 2.06 & 72.61 \\
\hline Flavone & 0.90 & -- & -- \\
\hline Phytosterol & 0.50 & -- & -- \\
\hline Anthocyanin & 0.12 & -- & -- \\
\hline Alkaloid & 1.90 & -- & -- \\
\hline
\end{tabular}

\subsection{Distribution of molecular weight}

It had been reported that the molecular weight of polysaccharides was an important parameter influencing antioxidant activity and low molecular weight showed high antioxidant activities [33]. In this work, the average molecular weight of the polysaccharides from Jatropha curcas L. seeds was estimated to be about $41.47 \mathrm{kDa}$. The polysaccharides have no absorbance at $280 \mathrm{~nm}$, suggesting that these polysaccharides do not contain protein. Furthermore, the weight-average (Mw) and number-average (Mn) of the polysaccharides were $41.47 \mathrm{~kg} / \mathrm{mol}$ and $19.05 \mathrm{~kg} / \mathrm{mol}$, respectively, which indicated that the polysaccharides had a relatively low index of polydispersity with a Mw/Mn value of 2.18 and a narrow molecular weight distribution [28].

\subsection{Ability of the polysaccharides to scavenge hydroxyl radicals}

Among the oxygen free radicals, the hydroxyl radical $(\bullet \mathrm{OH})$ is the most reactive free-radical, and it can severely damage nearby biomolecules, such as proteins, DNA, polyunsaturated fatty acids, nucleic acids, etc. [34]. Figure 2 depicts the hydroxyl radical effects of polysaccharides from Jatropha curcas L. seeds, and ascorbic acid. There is a concentration effect relationship with increasing concentration. As shown in Figure 2, the scavenging ability of polysaccharides on hydroxyl radicals increased rapidly as the concentration of the polysaccharides increased, within the range of $0.50-5.00 \mathrm{mg} / \mathrm{mL}$. The rate that polysaccharides and ascorbic acid scavenged hydroxyl radicals at $5.00 \mathrm{mg} / \mathrm{mL}$ was $97.01 \%$ and $99.74 \%$, respectively. These results suggest that the polysaccharides from Jatropha curcas L. seeds showed a remarkable ability to scavenge hydroxyl radicals with a scavenging range of $56.79-97.01 \%$, but the antioxidant activity of the polysaccharides is weaker than that of ascorbic acid. It has been reported that the hydroxyl group plays an important role in the antioxidation action among the functional groups of the polysaccharide molecule, and polysaccharides

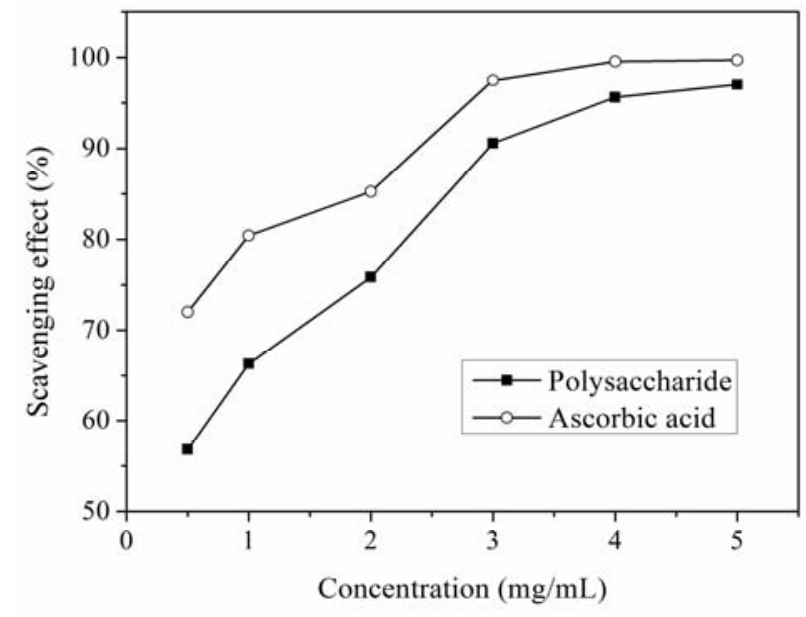

Figure 2. Hydroxyl radical scavenging activity of polysaccharides from Jatropha curcas L. seeds, and ascorbic acid. 
with low molecular weights have more reductive hydroxyl group terminals (on a per unit mass basis) to accept and eliminate the free radicals [35].

\section{Conclusion}

A new technology of cascade extraction and separation of active constituents of Jatropha curcas L. seeds was established. The Jatropha seed oil was obtained from ultrasonic extraction and the yield was $37.42 \mathrm{~g} / 100 \mathrm{~g}$ dry seeds. GC-MS analysis indicated that the oil contained five fatty acid methyl esters and that these were mainly unsaturated fatty acids. Polysaccharides and protein were obtained with high yield $(0.46 \mathrm{~g} / 100 \mathrm{~g}$ dry seeds and $2.06 \mathrm{~g} / 100 \mathrm{~g}$ dry seeds, respectively) and high purity $(75.72 \%$ and $72.61 \%$, respectively). Meanwhile, flavone, phytosterol, anthocyanin and alkaloid were qualitatively determined, and the contents were $0.90,0.50,0.12$ and $1.90 \mathrm{~g} / 100 \mathrm{~g}$ dry seeds, respectively. Moreover, the average molecular weight of the polysaccharides from Jatropha curcas L. seeds was estimated to be about 41.472 $\mathrm{kDa}$ and the rate of polysaccharide scavenging of hydroxyl radicals at $5.00 \mathrm{mg} / \mathrm{mL}$ was $97.01 \%$. Due to the presence of this remarkable antioxidant activity, the development of these polysaccharides as value-added products has been promoted.

\section{Acknowledgement}

This work was supported by the "Fundamental Research Funds for the Central Universities (NO. BLX2013006), the 948 Project from State Forestry Administration of China (No. 2014-4-35) and Beijing Natural Science Foundation (2142024).”

\section{References}

1) S. Sayyar, Z.Z. Abidin, R. Yunus, A. Muhammad, Am. J.Appl. Sci., 6, 1390-1395 (2009).

2) A. Emil, Z. Yaakob, M.S. Kumar, J. Jahim, J. Salimon, J. Am. Oil Chem. Soc., 87, 689-695 (2010).

3) J. Min, S. Li, J. Hao, N. Liu, J. Chem. Eng. Data, 55, 3755-3758 (2010).

4) S. Shah, A. Sharma, M. Gupta, Bioresour. Technol., 96, 121-123 (2005).

5) J. Martinez-Herrera, P. Siddhuraju, G. Francis, G. Davila-Ortiz, K. Becker, Food chem., 96, 80-89 (2006).

6) E. Oskoueian, N. Abdullah, S. Ahmad, W.Z. Saad, A.R. Omar, Y.W. Ho, Int. J. Mol. Sci., 12, 5955-5970 (2011).

7) R.K. Devappa, H.P. Makkar, K. Becker, J. Agric. Food Chem., 58, 6543-6555 (2010).

8) H.P.S. Makkar, K. Becker, Eur. J.Lipid Sci. Technol., 111, 773-787 (2009).

9) J.S. Roach, R.K. Devappa, H.P.S. Makkar, K. Becker, Fitoterapia, 83, 586-592 (2012).

10) R.K. Devappa, H.P.S. Makkar, K. Becker, J. Sci.Food Agric., 90, 2090-2097 (2010).

11) J. Zippel, A. Deters, Planta Med., 72, 230 (2006).

12) O. Ebuehi, N. Okorie, Nigerian Quar. J. Hosp. Med., 19, 200-205 (2009).

13) P.A. Corzo-Valladares, Á. Fernández-Cuesta, J.M. Fernández-Martínez, L. Velasco, J. Am. Oil Chem. Soc., 90, 1713-1718 (2013).

14) S. Ranjan, R. Singh, M. Singh, U.V. Pathre, P.A. Shirke, Plant Physiol. Biochem., 79, 48-59 (2014).

15) A.F. dos Santos, S.A. Fonseca, F.A. César, M.C.P. de Azevedo Albuquerque, J.V. Santana, A.E.G. 
Santana, Parasitology Res., 113, 1077-1084 (2014).

16) H. Lv, Y. Gao, H. Shan, Y. Lin, Carbohydr. polym., 107, 98-102 (2014).

17) J. Liu, C. Liu, Y. Rong, Solvent Extr. Res. Dev., Jpn., 19, 137-145 (2012).

18) P. Šimáček, D. Kubička, G. Šebor, M. Pospíšil, Fuel, 88, 456-460 (2009).

19) J. Miao, K. Che, R. Xi, L. He, X. Chen, X. Guan, X. Zhuang, X. Wen, Y. Cao, J. Am. Oil Chem. Soc., 90, 1503-1508 (2013).

20) M. Dubois, K.A. Gilles, J.K. Hamilton, P. Rebers, F. Smith, Anal. Chem., 28, 350-356 (1956).

21) T. Masuko, A. Minami, N. Iwasaki, T. Majima, S.I. Nishimura, Y.C. Lee, Anal. Biochem., 339, 69-72 (2005).

22) J.J. Sedmak, S.E. Grossberg, Anal. Biochem., 79, 544-552 (1977).

23) M.a.I.N. Moreno, M.a.I. Isla, A.R. Sampietro, M.A. Vattuone, J. Ethnopharmacol., 71, 109-114 (2000).

24) H. Liu, N. Qiu, F. Wang, Y. Zhao, H. Xu, China Oils and Fats, 11, 022 (2008).

25) R.B. Broadhurst, W.T. Jones, J. Sci. Food Agric., 29, 788-794 (1978).

26) P. Zhao, J.Y. Liu, Y.P. Zhang, China Food Addit., 3, 039 (2011).

27) S. El-Masry, M.A. Korany, A.H.A. Abou-Donia, J. Pharm. Sci., 69, 597-598 (1980).

28) F. Peng, J.L. Ren, F. Xu, J. Bian, P. Peng, R.C. Sun, Food Res. Int., 43, 683-693 (2010).

29) J. Bian, F. Peng, F. Xu, R. Sun, J.F. Kennedy, Carbohydr. Polym., 80, 753-760 (2010).

30) L.D. Mei, S.J. Wen, Q.H. Min, Z.W. Fen, H.C. Ming, X.X. Long, J. Med. Plants Res., 5, 3061-3066 (2011).

31) Y. Vaknina, M. Ghanim, S. Samra, L. Dvash, E. Hendelsman, D. Eisikowitch, Y. Samocha, Ind. Crop Prod., 34, 1029-1034 (2011).

32) H.J. Berchmans, S. Hirata, Bioresour. Technol., 99, 1716-1721 (2008).

33) W. Zeng, Z. Zhang, L. Jia, Carbohydr. Polym., 108, 58-64 (2014).

34) X. Zhang, L. Liu, C. Lin, Food Hydrocolloids, 39, 10-18 (2014).

35) D. Liu, J. Sheng, Z. Li, H. Qi, Y. Sun, Y. Duan, W. Zhang, Int. J. Biol. Macromol., 56, 1-5 (2013). 